\title{
THE RESEARCH APPROACH TO STUDYING \\ THE CONSCIOUSNESS IN THE EDUCATIONAL WORK WITH STUDENT-PSYCHOLOGISTS
}

\section{Vintyuk Yuriy ${ }^{1}$}

DOI: dx.doi.org/10.30525/978-9934-571-30-5_9

Abstract. Thepurpose of the work: to elucidate the features and application of the research approach to the study of consciousness in the educational work with the student-psychologists. The methods that are used in this paper are analysis, synthesis, systematization, specification, generalization. Methodology. The research is based on the works of foreign and domestic scientists, which contain important methodological approaches to solving the problem of consciousness. It is provided methodological foundations for the consideration of issues related to the clarification of its origin, essence, features of the functioning, and the practical application of this knowledge in the articles of the scientists, who were involved in the study of this problem. Results. As a result of the analysis of publications on the subject matter, the peculiarities of forming the competitiveness of future specialists in higher educational institutions in the present conditions have been established. Referring to them, a model of the process of forming the competitiveness of future professional psychologists in the process of their training in higher education has been developed. The approbation of the proposed model in the real educational process of training of future professional psychologists in universities is implemented. Practical implications. The practical implicationof the paper is that, as a result of the research, an approach was developed, which implements the optimal approach to familiarizing students with the study of consciousness and allow to rationally combine the existing disparate knowledge of the subject of the presentation and present them clearly and in a strictly logical sequence, based on the needs of students in such knowledge, the existing level of knowledge and training requirements. The application ofthe developed approach allows to solve the practical problems arising in the study

\footnotetext{
${ }^{1}$ Candidate of Psychological Sciences, Associate Professor at Department of Theoretical and Applied Psychology, Lviv Polytechnic National University, Ukraine

(C) Vintyuk Yuriy
} 
of this subject matter by future psychologists and overcome the difficulties related to its study. Value / Originality. The developed model of the process of formation of the competitiveness of future psychologists in the process of professional training involves: the formation of their professional competence, the enhancement of the practical component, in particular, the implementation of a research approach,the internship, mastering of computer technologies, the involvement in research work, mastering of foreign languages and teaching a special course "psychology of a competitive personality". The model adequately reproduces the real process of training of future professional psychologists in higher education institutions, and after approbation and updating it can be recommended for introduction into the educational process.

\section{Introduction}

The training of specialists with higher education in modern conditions requires the application of appropriate approaches that allow us to trace the course of the development of science, the process of acquiring knowledge within the various currents, directions and schools, which is necessary to form ideas about its current state. This circumstance also applies to the training of future professional psychologists: students should receive adequate ideas about the basic concepts of psychological science. It is important for their further successful professional development. The notion of consciousness belongs to the concepts, which require careful study, beginning with the first course of training, and only theoretical knowledge is not enough for its full understanding. This circumstance makes it necessary to introduce a research approach to the educational process, which involves the application of research elements at various stages of it; this confirms the relevance of this work.

The main problemcovered in this article is that it is difficult for the firstyear students, who become acquainted with the phenomenon and manifestations of consciousness within the course of "General Psychology" to master the essence of this psychological phenomenon, understand the existing approaches to explaining its functioning, and comprehend the accumulated knowledge and research methods by which they were obtained. Therefore, there is a contradiction in the preparation of future psychologists, which requires the application of an appropriate approach that would help to resolve it. 
The purpose of the work: to elucidate the features and application of the research approach to the study of consciousness in the educational work with the student-psychologists.

\section{Objectives of the study:}

- to review the scientific publications on the subject matter;

- to clarify the subjects and approaches to the study of consciousness;

- to elucidate the features of the study of consciousness in different periods;

- to consider the specifics of attracting students to the research of consciousness, at each stage of its study;

- to draw conclusions from the work done and outline the prospects for a further research in this direction.

This work was implemented in the context of previous studies on the formation of professional competence of future professional psychologists and also is their further continuation (see, eg: $[4,5]$, etc.).

\section{The analysis of recent research and publications}

Modern scientists often turn to the study of consciousness, although these studies do not belong to priority ones. Accordingly, few scientific publications, both domestic and foreign scientists, have been published on the actual problems of the researches of consciousness. First of all, it is necessary to mention that the works of predecessors, which have not lost their significance until now, since they contain important methodological approaches to solving the problem of consciousness. These are publications by A. V. Eractin [10], A. N. Leontiev [11], A. N. Loya [13], O. R. Luria [14], M. K. Mamardashvili [15], F. T. Mikhailova [17], A. G. Spirkin [23] and others.

It should also be noted that the further researches, both domestic and foreign scientists, areelucidated in the works of S. Avramenko [1], A. Yu. Agafonov [2], S. Grofa [7], M. Jeffrey [8], E. Neumann [18], H. Pantem [20], G. T. Hunt [26] et al.

Among the newest publications, it is worth noting the scientists involved in the development of the psychosemantic theory of consciousness: O. Artemyev, V. Petrenko, V. Serkina, Yu. Timosh, O. Shmelev [citation. for 25] and others.

A wide range of issues related to the clarification of its origin, essence, features of functioning, and the practical application of this knowledge was reviewed in the works of scientists, who were engaged in the study of the phenomenon of consciousness. An overview of literary sources is not pro- 
vided since the volume of publication is limited. However, some of the necessary provisions are given in the course of the presentation of the material of our research.

Despite the fact that the main provisions of the essence, origin, features of the study and functioning of consciousness in the existing scientific literature on the subject matter are fully elucidated, there is no information on how it is advisable (on a rational basis)to familiarize the student-psychologists with this knowledge and presentation of practical experience of such work. Since separate scattered data do not provide a coherent picture of the phenomenon being studied, this circumstance requires the application of an appropriate approach that would allow us to master not only the available theoretical knowledge, but also practical skills in the study of consciousness, and also indicate the possibilities of applying this knowledge. It is necessary to illuminate this aspect of the problem in an independent study.

\section{Presentation of the main research material}

The study consisted in an attempt to develop and implement a certain optimal approach to familiarizing students with the study of consciousness. This approach would allow to rationally combine the existing disparate knowledge of the subject of the presentationand present them clearly and in a strictly logical sequence, based on the needs of students in such knowledge, the existing level of knowledge and training requirements. To create such an approach, a special study has not been implemented, the existing experience of teaching has been used, and accordingly, its formation cannot be considered complete. In implementing the approach, the task has been to bring scientific theoriesas close as possibleto the everyday life of each personand make them understandable forthe students. At each stage, the study contains both an analytical and a practical component, organized and conducted by the teacher, but with the maximum possible involvement of the students. It is accomplished both in the audience activity and the education outside the audience. An expedient sequence of conducting the investigation, both the presentation of the material and its practical component, in an abbreviated form, is given below.

\subsection{Background to the study of consciousness}

The presentation of the topic begins with familiarizing the students with the beginning of the accumulation of knowledge about human conscious- 
ness. It is noted that the researchers were interested in this problem at different times, beginning with Antiquity, but then, as well as later, they were interested primarily in disorders of consciousness that determined the possibility of a person to be a full member of society and her ability to productive activity, as well as changed states of consciousness, in connection with mystical and religious practices. In addition to healers and cult attendants, philosophers were also engaged in the study of consciousness, but they were primarily interested in purely philosophical aspects of the problems associated with it, while soothsayers,magicians and shamans practised the practical questions of the influence on the psyche, derived from experience. This situation remained until the emergence of the philosophical and theoretical substantiation of the problem of consciousness, which was done in the works of Rene Descartes and JohnLocke in the 17th century (which the students know from previous subjects). Further, it is advisable to remind the students of the main provisions developed by these scientists and their followers. It is also worthwhile to invite them to take part in the discussion on this subject matter in order to clarify their level of understanding of these provisions.

R. Descartes suggested understanding the psyche as the inner world of a person, which is open to self-observation and has a special spiritual being, as opposed to the body and the external material world. Their absolute heterogeneity and the fundamental difference are the main points of his doctrine. R. Descartes asserted that the body, which acts as a machine, is capable of successfully coping with the processing of information, which enters the brain. He assigned a special role to the soul. R. Descartes not onlydid not deprive it of the former royal role in the universe but also he brought it to the degree of substance - the nature that does not depend on anything else - that is, an equally large substance of nature. The soul must have a reliable knowledge of the subject about its own acts and states, which are invisible to anyone else. Accordingly, the soul can be identified by the only sign that is the direct awareness of own phenomena, which, in contrast to the phenomena of nature, are devoid of length. The act of the existence of the soul, according to R. Descartes, is expressed in the presence of thinking.

However, another approach was implemented in the works of J. Locke, where experience was called the source of knowledge andrationality was countered with empiricism. He defended the idea of the origin of the whole content of human consciousness from experience. J. Lockedistinguished 
two sources in the experience: a sensation and reflexion.Together with the ideas that the senseorgans bring, there are ideas generated by reflection as "the inner perception of the activities of our minds." The development of the psyche is due to the fact that simple ideas form the complex. All ideas appear in a court of consciousness. "The consciousness is a person's perception of what is happening in her own mind," thought J. Locke.

Then, we need to mention both the perception of contemporaries and the continuation of the development of the ideas of R. Descartes, J. Locke and other thinkers. After that, it is worth asking what students think about it. However, philosophical-analytical, as well as mystical-practical methods of studying the consciousness are not suitable for the training of practical psychologists at the present level but they are important starting points for continuing the presentation.

\subsection{The beginning of scientific research of consciousness}

From the beginning of the emergence of the first direction of scientific psychology - structuralism of Wilhelm Wundt, the subject of the research was consciousness, and the method of research - introspection. He wanted to build psychology as a natural science discipline. Accordingly, the scientist defined it as a science about the properties of consciousness, the elements of consciousness and the connection between them. It is necessary to explain to the students how exactly the researches of consciousness were implemented by the method of introspection, as well as the main points of the structuralism, constructed on them.Understanding this methodfrom the point of view of the achievements of that time and modern interpretations are available in the special literature (see, for example: [6;22], etc.). These positions are given, explained and discussed. If it is necessary, individual questions are given to the students for their own work.

Introspection is a method of psychological research, consisting of the researcher's observation of his own feelings, thoughts, etc. That is self-observation of a person in terms of the content and acts of her own consciousness. It lies in the in-depth study and knowledge of the person's moments of her own activity: separate thoughts, images, feelings, experiences, acts of thinking, etc. That is self-analysis, which was proposed by R. Descartes and then developed in the writings of J. Locke, who, in particular, distinguished the inner and outer experience of man. The first (internal) experience is achieved through introspection (self-observation, self-study). The 
second experience is directed to the outside world. Subsequently, W. Wundt combined the method of introspection with instrumental methods. One of the directions of introspective psychology is the doctrine of "internal experience", from which psychic phenomena are recognized in a fundamentally different way than material ones. This direction of psychology should be considered as an important stage in its development and methods developed by introspective psychology deserve attention. After all, almost all modern psychologists think that the consciousness is a set of phenomena, some of which can be studied with the help of self-observation, that is, introspection.

Based on his researches, W. Wundt distinguished the first property of consciousness - organization,structuredness. It is the structure of organized elements. These elements are objective and subjective. In W. Wundt's terminology, the single objective element of consciousness is a simple impression. It means that it does not decompose into smaller units. An indivisible element of consciousness is a feeling, for example, the feeling is a simple impression that occurs when we hear a separate hit of a metronome, and if two strikes or more, then this is images. Accordingly, feelings and images are the objective elements of consciousness. The subjective elements of consciousness are internal elements that associate with the subject and come from it. Such elements of consciousness are feelings (emotions). According to W. Wundt, the consciousness is organized. The elements in the field of consciousness form links and they are structured. Thus, the field of consciousness represents a structure. There is a central point at the centre of this structure - that is what we draw attention to. This point (the focus of attention) is also surrounded by a certain area. We can say that around this point there is a central part of the field of consciousness, which is called the field of attention [21].

At this stage of the problem's disclosure, students still do not dare to express their attitude to the received knowledge, nor do they repeat some of the experimental studies of $\mathrm{W}$. Wundt and his followers, which have been suggested to them. That is, they are not included in the research process. From this, it follows that mastering of even the first stages of experimental studies of consciousness will not be easy. It is clear that in this case, the students encounter with the difficulties such as the lack of experience of observing their inner world, the content of their own consciousness, as well as the lack of notions about the connection of the content of consciousness with reality and the possibilities of practical application of this knowledge. 
It is necessary to return at least a century ago and tell students about how the development of the content of consciousness began, on the example of fiction, since they are not badly acquainted with it.

\subsection{The research of consciousness in literature}

In the eighteenth century in the fiction, there was a forerunner of a psychological novel - a sentimental novel, the founder of which was the English writer L. Stern. Sentimental writers favoured human feelings and the focus of their attention was the image of the inner world of their heroes. Therefore, it is advisable to use the fragments from their works in order to illustrate the content of human consciousness in different situations. Thus, the students have been offered a fragment from L. Stern's novel "A Sentimental Trip to France and Italy", in which there is an episode where the protagonist sits in a diligence that stays in a closed barn and nothing seems to happenin the whole chapter at all. The question to the presents: "What do you think the author writes about in the whole chapter as there are no visible actions?" It becomes apparent that he writes about his thoughts, experiences, memories. That is, the story does not become poorer due to the lack of action. The students are astonished by such a turn of affairs, but they have also recalled other similar well-known moments from various works of art and films. This indicates that such a phenomenon is known to them. Now, it will be appropriate to ask the presents: "What is happening at that time in their consciousness when they seem to be sitting still on the lecture in the audience? It is found that the familiar world was depicted by sentimentalists. Although the students acknowledge it, they tell reluctantly about what is happening in it. We note that it is L. Stern, who is most involved in the discovery and elucidation of the depths of the inner world of a person, who subsequently received a continuation in a psychological novel.

Further, it is expedient to proceed to the consideration of the evolution of this literary tradition, beginning with the first half of the nineteenth century, when a psychological novel appeared as an independent genre.Its founder was the French writer Stendhal. In the second half of the century, the most perfect psychological novels were created by Russian writers L. Tolstoy and F. Dostoevsky (the students are known with the works of these authors). They made an important discovery, which had an impact on the further development of not only world literature but also the psychological analysis. Prior to this, the phenomenon of thought was comprehended as a simple 
response of consciousness to the fact of reality, that is, the thoughtcorresponded to the fact and was equal to it. However, L. Tolstoy showed that people were like rivers: the spiritual world is flowing, the thought only proceeds from the fact, all previous experience of the person is involved in the act of thinking, and the thought combines the present, the past and the future. It is engaged in the processing of the fact in the light of life experience of the person. The analytical and synthetic ability of the brain, as well as memory, imagination and fantasy, are involved in the act of thinking. It is found that analytical awareness, the description of the fact that goes back into the past, is "symmetric" in relation to the future, prophecy and prediction [12]. Consequently, we note that a psychological novel is a kind of novel, in which the author sets the goal of representation and study of the "internal states of human" and "the subtle movements of her soul". It is the content of herconsciousness. As examples of its reproduction in a psychological novel, it is expedient to use fragments from the works of representatives of this genre. They should be discussed and analyzed with the maximum involvement of students.

The modern psychological novel of the twentieth century continued a further evolution of a genre of a psychological novel, as well as the study of the inner world of a person. However, its appearance was preceded by important events in the scientific worldrelated to the development of scientific psychology at the turn of the nineteenth and twentieth centuries. A new phenomenon in the literature that was spreading and evolving over a century did not go unnoticed by psychologists. Scientists would certainly be interested in it, at least because writers using artistic means tried to solve the same tasks, which psychologists also faced - to clarify the content of consciousness and explain on this basis the actions of a person.

\subsection{The stream of consciousness in psychology}

The most important next milestone in this series of events, which had a significant impact on the further study of consciousness and, consequently, the formation of psychology as well as fiction: an American psychologist William James introduced the term "the stream of consciousness" in the work "Fundamentals of Psychology" (1890). He thought that the consciousness of a person is like a stream of a river, in which thoughts, feelings, associations interrupt each other and illogically intertwine. It is known that for the first time, "the stream of consciousness" was used by the French prose 
writer E. Dujardin in the novel "The laurels are all cut" (1888). Much earlier such an attempt was made by L. Tolstoy, in the story "The History of Yesterday", 1851. The term proposed by W. James combines various types of internal monologue (literary description of internal processes of thinking, the technique of image of thoughts and feelings passing through the consciousness, an image of spiritual processes) [12]. The consideration of the main provisions regarding the concept of "the stream of consciousness" and their analysis is of major interest from the point of view of the topic's disclosure and the implementation of stated tasks. It is advisable to start this work from the work of W. James [9], (however, it is also necessary to review the contemporary views on the subject, for example: [19]). At first, it is noted that this is a different point of view on the same problem since the author criticizes the positions of structuralism of W. Wundt and E. Titchener.

W. James begins his deliberation with the following statement: The primary concrete fact that belongs to the inner experience is the belief that in this experience some conscious processes take place. The states of consciousness change each other in it. Just as we express ourselves impersonally: "light", "dark", we can also characterize this fact better by the impersonal verb "thought". The scientist reflects on how conscious processes are implemented and notes that there are four essential features in them: 1) each state of consciousness tends to be a part of personal consciousness; 2) its conditions are changing within the limits of personal consciousness; 3) any personal consciousness is an uninterrupted sequence of feelings; 4) it accepts some objects willingly, rejects others and, in general, it is constantly choosing between them [9]. These provisions are put forward for the discussion. If it is necessary, the fragments of their further consideration in the work of W. James are given. Students are asked to elucidate the essence of this phenomenon and formulate its definition.

As a result of the joint discussion, it is stated that the stream of consciousness is a continuous series of mental reflections (thoughts, representations, memories, feelings and images, etc.), which is presented in the human psyche, accessible to self-observation and constitutes its internal psychic reality. Then, tasks are gradually becoming more complicated, it is suggested clarifying: What does the consciousness record at every moment of time? What are the laws of this reflection? It becomes apparent that the consciousness does not record anything insignificant. It constantly searches and selects the most important, vital information, suitable for use. This 
information flows simultaneously on many channels, and the consciousness constantly scans it, finding the right one and relevant at the moment. However, it is not possible to clarify the origin and purpose of a number of elements of consciousness. It is even more difficult to trace their sequence and the connection between them. This stage of the discussion ends with the formulation of the definition: the stream of consciousness is the continuous process of reflecting the phenomena of reality by the consciousness in all their diversity.

W. James further discusses: "The consciousness is in constant change. By this, I do not mean that noneof the states of consciousness has any length, even if it was true, it would be extremely difficult to prove it. I just want to emphasize the fact that none of the state of consciousness that has passed, will be able to literally reappear and repeat itself. We listen to it, then we discuss it, we recall it, we anticipate it, we love it, we hate it, our mind is quietly occupied by thousands of different objects of thought" [9]. As a result of the consideration of the reasons for such variability in the content of consciousness, the author notes: "It seems to me that the analysis of integral, specific states of consciousness that are replacing each other is the only true psychological method, no matter how difficult it is to strictly conduct it through all the nuances of the research. At first, it seems to the reader to be dark, then with the further presentation, its meaning will become clearer." This idea best reflects the essence of the proposed and used approach. The students consider it and they also agree with it. It should be noted that, soon after, W. James's position is also criticized by representatives of other psychological directions, which also deserve careful consideration and analysis. That is, the task is complicated: it is necessary not only to look for confirmation of the position, which proves the author but also to prepare counterarguments.

However, we need to come back to the work of W. James, who further draws attention to the fact that in the stream of consciousness, its various parts have a different velocity of the stream. "The points of stops in the consciousness are usually occupied with sensory impressions, the feature of which is that they can, without changing, be indefinitely contemplated by the mind. The transition intervals are occupied with thoughts about the relation of static and dynamic, which is basically established between objects perceived in a state of relative calm" [9]. That is, in the consciousness periodically there is the receipt of information from the sense organs, then it 
is processing by the brain. This fact seems obvious, although, before this, none of the participants in the study has expressed such an opinion on the regularities of the work of consciousness. W. James came to the idea that our thinking is constantly striving from one stable part that has just been left to another. We can say that the main purpose of the transitional parts of consciousness is to direct us from one lasting, firm conclusion to another.

After the necessary explanations, the students are asked to name all the components and schematically depict the structure of the stream of consciousness. (A detailed consideration of this issue, as well as an analysis of the answers given, deserve particular elucidation). The scheme consisting of the mentioned components is simultaneously drawn on a blackboard. Further, with the help of existing knowledge, the examples of literature and the developed scheme, the students are encouraged to record and reproduce their own stream of consciousness, at the present time and for a certain limited period of time. With appropriate preliminary training, they are included in the research process. After checking their works, the best of them are published and discussed, as well as the reasons that prevented other students from coping with this task are found out. In any case, an existing barrier that prevents even the most active and well-prepared students from engaging in the proposed study process has been overcome. However, the study continues, and other participants are gradually being joined to it.

\subsection{Understanding psychology and studying of the consciousness}

According to a further logic of the presentation, it should be noted that the direction of psychological researchappearedin the late nineteenth century. Its aim was to comprehend the inner world of human on the material of works of art. It was initiated by the German philosopher Wilhelm Dilthey, who deemed that psychology, based on the explanatory methods, which were borrowed from the natural science, could not give a holistic understanding of human as a real, living person. Her place should be understood by understanding psychology, according to which the main task of psychological research is not the causal explanation of the mental life of human and understanding through the correlation of its internal meaningful formations (experiences) with the world of cultural and historical values. He asserted: "We explain nature, and we understand the spiritual life". The basis of this idea was the opposition of the natural science to the science of society and the denial of the very opportunity to study the socio-historical 
conditionality of the human psyche with the help of the objective methods, including experimental and scientific ones [3, p. 127].

W. Dilthey accepted the division and contrasting of the science of nature and the science of the spirit. The natural science only has access to experience and it gives only pale shadows of "hidden reality". The science of the spirit is directed to internal experience and its subject is self-consciousness. The natural science realizes the knowledge that is available to the sense organs such as sight, hearing, taste and observes the discerned facts and establish connections between them. The science of the spirit deals with the hidden, inaccessible to the external sense organs of reality that are recognized by experience, intuitively captured totality (integrity) of life. W. Dilthey contrasted the explanation made with the help of reason in the science of nature on the basis of causality, analysis, systematization, logical derivation, etc., and understanding, realized in the science of the spirit and the intuitive penetration of one life into another. The method of understanding consists in direct comprehension of some spiritual integrity. According to the scientist, we explain nature, and we understand the spiritual life.

W. Dilthey distinguished between the natural science psychology and the spiritual-scientific psychology. The first one identifies isolated, unambiguous, certain elements ("atoms") in the consciousness and applies the method of explanation - this is explanatory psychology. W. Dilthey criticized such a psychology for spreading the concepts of natural science in the area of spiritual life and argued that its hypotheses of "atoms" are unproven. Spiritual-scientific psychology is "descriptive". It comprehends the connections of spiritual life teleologically and represents the internal experience of the psychic sphere as a connected integrity and semantic formations, included in the history of culture. In this psychology, the main thing is not the causal explanation of spiritual life, but its understanding by correlating the internal semantic formations (experiences) with the world of cultural and historical values. W. Dilthey thought that the understanding of your own inner world is accomplished through introspection (self-observation), and the spiritual world of another is accomplished through "empathy", "use", "coherence". He came to the conclusion that the inner experience, in which occurs self-absorption in your own states, does not make it possible to realize your own individuality: you realize your individuality only in comparingyourself with other people, [3, p. 356]. The necessary for this material was available in artistic works, mainly in psychological novels. 
Understanding, being converted to the culture of the past, implements the interpretation and interprets individual phenomena as elements of the spiritual life of the reproduced era. Such understanding-interpretation of W. Dilthey is called hermeneutics (from the Greek - I explain, interpret). Understanding involves the penetration into the spiritual world of the author of the text that includes the reconstruction of the cultural context, in which the text has been created. This understanding introduces subjective experiences in semantic connections that exist outside the subject of spiritual culture - in art, religion, morals, and law.

The main task of understanding psychology is to reveal the meaning of the spiritual life of the human and the system of her values. "It is impossible not to wish for the emergence of psychology, which is able to capture in the net of its descriptions what is contained more in the writings of poets and writers than in the present teachings about the soul." - wrote W. Dilthey. The subject of such psychology should be the development of mental life in its entirety. Descriptive psychology at the same time should be analytic, and the analysis should include a living, artistic process of understanding. Understanding psychology sought to obtain and gather information about the elements of consciousness, which are necessary and sufficient to present the entire course of individual mental life. According to W. Dilthey, good psychologists are writers, historians, actors, teachers, doctors [3, p. 356].

Since it is actually proposed to take advantage of the achievements of literature, namely the accumulated actual material about the content of consciousness and the peculiarities of its functioning, in order to solve the problems of psychology. The above provisions are an appropriate justification and serve as a reference point for the continuation of the presentation.

\subsection{The psychological novel of the twentieth century: the change of the paradigm}

Theachievements of psychological science in the field of study of consciousness at the turn of the nineteenth and twentieth centuries had a significant impact not only on the psychology and literature of the future but also on the further development of art in general. Given this, we need to tell about the emergence and development of a modern psychological novel. The theoretical positions of the "stream of consciousness", developed in psychology, soon not only returned to literature again but also changed it, creating the art of the future (in fact, there was a change of artistic paradigm). The 
beginning of this process was set in 1915 when the French writer M. Proust published the first book of the novel "In Search of Lost Time", in which he used the art technique of representation of "the stream of consciousness". As a result, the art achieved a qualitatively new level through the discovery and development of new opportunities. According to modern ideas, in the literature, the "stream of consciousness" is an artistic means of representation of the inner world of a person, consisting in the direct reproduction of the stream of her thoughts, experiences, mood as a complex psychological consciously-subconscious process, a peculiar way of fixing and expressing the most concealed components of this process [12].

Then, the students need to be told about the main achievements of the psychological literature of the twentieth century, first of all about the works of J. Joyce [16] and W. Wulff [1], as well as other representatives of the school of "the stream of consciousness" in fiction [24]. Also, it is necessary to bring fragments of their works andimplement their analysis from the standpoint of psychology.

In addition, the students are encouraged not only to become acquainted with the main achievements of psychological artistic prose, but also regularly read the works of psychological direction, including modern ones, and also to review films, created on their motives, analyze them, etc. The students are independently offered to study the current state of both psychological prose and modern psychological novel.

After conducting an analytical research, it is necessary to consolidate the knowledge gained, as well as to provide practical skills for their application. As a result of the training, the students begin to join the research of consciousness using the method of introspection.Having received the necessary number of examples, they reproduce the experiments of the late nineteenth century. Then, they are asked to analyze both the method itself and the results obtained during the study with the achievements of the psychology of the twentieth century that is known to them, as well as their own experience. After this, it is necessary to familiarize the future psychologists with modern scientific ideas about the subject of the research.

\subsection{Modern scientific notions of consciousness}

At the beginning of the presentation of modern ideas, we state that the difficulties of understanding and studying the consciousness are due to the fact that we cannot,directly, sensually,observe its phenomena, measure 
them and explore with the help of various devices. Indeed, at any level of the study of the human brain, it does not fix what is called the thought, although the brain cannot be investigated otherwise, but only on the basis of the thesis that it is an organ of thought and consciousness. In this connection, the statement has been repeatedly expressed that the consciousness as a special entity does not exist at all, that it can be reduced to functions of the reaction of the nervous system to the external factors.

In the twentieth century indeed, a number of works have been published to prove that in reality there is nothing that could be called mental phenomena or consciousness. The interpretation of consciousness as a special form of reflection of reality is widespread, but in this case, it is deprived of the ontological status, since it is considered that it does not introduce anything fundamentally new in reality. Accordingly, the consciousness as a form of reflection of reality is endowed with the ability to only reproduce and combine existing forms of being. The students are reluctantly involved in the discussion about this, so then it is necessary to tell about the main signs of consciousness.

The first of the signs of consciousness is considered a special, inherent only to a person, type of behaviour, which is not reduced to biologically appropriate adaptation to the requirements of the environment. Its presence is evidenced by the direction and meaningfulness of human actions, the manufacture of tools of labour and livelihoods. All these tools become a new environment for human life. The students will learn more from the presentation of the relevant subject matter, which is provided in this course, about a specifically human type of behaviour that is called activity.

The other feature is the ability to operate with the content of reality, which is not given clearly. With the help of consciousness, people are capable of seeing something that does not exist in the present form. Consequently, the functioning of consciousness is connected with a special substantive content of reality, which is not given to us sensually but is based on experience in a particular socio-cultural environment. This is precisely due to the purposeful character of human activity, the ability to create images of future necessary results of action, and therefore, a person is capable of creating something that does not really exist.

Another sign of consciousness is the ability to operate with signs and sign systems, among which the most important role belongs to the language. The availability of language and speech is the main sign of the presence of 
consciousness that is necessary for a person to fix the content that can not be conveyed by anordinary demonstration of the things. Therefore, the language becomes the main bearer of the historical experience of all mankind and plays a leading role in its development.

No less important sign of consciousness is that, although it is not fixed by any devices, it is capable of fixing itself, which is manifested in the ability of self-awareness and is a self-reflection of consciousness. The moment of the substantiality of consciousness manifests itself in it. That is, the moment when the consciousness for the sake of its existence does not require any external reinforcements, since it finds its own obviousness in itself, which also gives a person the opportunity to become the subject of knowledge and activity, that is, to produce her own activity from herself and on her own. The basic signs of consciousness are also subject to the discussion.

Further, we turn to the consideration of the question of the functions of consciousness. Previously, it is worth asking the students: "Who are they, in their opinion?" After a brief discussion, we continue the presentation: according to the modern scientific concepts, the consciousness performs the following functions: cognitive, regulatory, prognostic, reflexive and communicative. The cognitive function is manifested in the accumulation, processing and use of information about the surrounding reality; the regulatory function controls the behavioural and emotional manifestations; the prognostic function is to build images of the future and plan a future life; the reflexive function is manifested in the discovery by a person of herself as a subject of mental activity; the communicative function of consciousness is to organize and maintain communication with other people.

In addition, the structure of consciousness should be considered. Despite the fact that the manifestations of consciousness have a systemic and integrated character, the structure with the components such as the knowledge, the attitude, the purposefulness of activity and the self-consciousnesshas been developedto study this phenomenon. Moreover, the structure of consciousness is interrelated with its functions, so each component is responsible for a certain function, such as knowledge is responsible for the cognitiveandprognosticfunctions; the reflexive function is provided by the work of self-consciousness, etc.

As alternatives to the existing images in the official science, it is also necessary to tell about the main provisions of transpersonal psychology [7]. 


\subsection{The conclusion and prospects of the study}

It is advisable to ask the following question before the conclusion of the study: What new can today be said about the content of consciousness, taking into account the achievements of modern psychological science? What new features of consciousness have been discovered? What has new methods of research been developed and used? Sincea person does not just observe a random sequence of perceptions:she feels and realizes needs, forms motives, acts - that is, she manages the stream of perceptions. The streamhasorientation and selectivity; a person perceives some images, while others she createson her own.The task is to compile an algorithm of consciousness work and implement it in the form of a computer program. At this stage, theresearch has to be discontinued because students are very little acquainted with the achievements of modern psychology and with programming languages. However, it has no bad prospects, considering the possibility of continuing it in the future. With high probability, the knowledge and experience acquired during the study, in which students have been involved, can be implemented later on a new level.

With respect to the results of the implementation of a proposed research approach in the educational process, the following should be noted. The students have been for the first time demonstrated the process of development of science, acquisition and accumulation of scientific knowledge, within the framework of a single, concrete and accessible for their understanding approach.

This has allowed to show them another side of psychology (not from the "front entrance", through the textbook, but from the "service entrance" - through the researcher's laboratory) and attract them to a peculiar "ritual of sacred activity", which constitutes a sacrament of science, accessible only to the elect. It has also allowed actualizing their interest in scientific research, studying the methods and procedures of conducting them, analyzing the results obtained and implementing generalizations. The conducted work has also contributed to the formation of motivation for engagement in research work in the most trained students. They have understood how scientific problems arise and formulate, and how the methods of their research are developed, and so on. And the most important thing is where the knowledge that is placed in textbooks on psychology comes from, which, in turn, contributed to the formation of a 
different attitude towards them, as well as to the process of their professional training at the university.

Similar researches should be continued by introducing a research approach to the learning process and teaching other training courses. This path seems fruitful, considering both the imperfection and the low effectiveness of existing traditional approaches and the methods of teaching, as well as the experience of conducting this research. Besides, theresults that have been obtained allow to optimistically evaluate the future prospects for its continuation, implementation and dissemination.

\section{Conclusions and prospects of the study}

The conducted research makes it possible to draw the following conclusions.

1. The review of scientific publications on the subject matter allows us to state that the existing works contain only a certain set of disparate data that are difficult to unite into a holistic concept suitable for teaching and understanding by students, which creates certain difficulties both in its teaching and mastering by students.

2. The application of the research approach to elucidating of this subject matter in the course of its teaching student psychologists allows to systematize the existing knowledge, expound it in a certain logical sequence and make it more accessible and understandable, as well as, form a positive motivation for its study and overcome a number of difficulties associated with its development.

3. The introduction to the proposed approach makes it possible to raise the interest in studying of this subject matter among students and interest them in the independent study of other aspects, methods and perspectives of consciousness research, which has a positive impact on their involvement in research activities, as well as on the process of their professional development in the course of a professional learning.

In the future, it is planned to elaborate this approach to the level of scientific-methodological development of studying by students the speciality "Psychology" with a further introduction into the educational process this subject matter, as well as continue the researchof other subject matters with the application of this approach to studying the educational disciplines. 


\section{Vintyuk Yuriy}

\section{References:}

1. Avramenko S. (2014). Potik svidomosti yak zasib vyrazhennia vnutrishnoho svitu personazhiv (na materiali romanu Virdzhynii Vulf "Khvyli"). The stream of consciousness as a means of expressing the inner world of characters (based on Virginia Wulf 's novel "Waves"). Visnyk of Lviv University. Foreign Languages Series. 22, 241-247 (in Ukr).

2. Agafonov A. Yu. (2003). Osnovy smyslovoi teoryy soznanyia. Fundamentals of the semantic theory of consciousness. St. Petersburg: Rech' (in Rus).

3. Bolshoi psykholohycheskyi slovar. Large psychological dictionary (2002). Edited by B. G. Meshcheryakova, V. P. Zinchenko. St. Petersburg: Piter (in Rus).

4. Vintyuk Yu. V. (2017). Kompetentnisnyi pidkhid u pidhotovtsi maibutnikh fakhovykh psykholohiv u VNZ. The competent approach in the training of future professional psychologists in the university. Young Scientist, \# 3 (43), (245-249) (in Ukr).

5. Vintyuk Yu. V. (2017). Kontseptsiia formuvannia profesiinoi kompetentnosti maibutnikh psykholohiv u VNZ. The conception of formation of professional competence of future psychologists in the university. Young Scientist. \# (44), 351-355 (in $\mathrm{Ukr}$ ).

6. Hippenrreiter Yu. B. (1988). Metod yntrospektsyi i problema samonabliudenyia. The method of introspection and the problem of self-observation. Introduction to general psychology. Moscow: Izd. MGU, 34-47. (in Rus).

7. Grof S. (2001). Kosmichna svidomist. Space consciousness. Kyiv (in Rus).

8. Jeffrey M. (1995). Korinnia svidomosti. Roots of Consciousness. Kyiv (in Rus).

9. James W. Potok soznanyia. The Stream of consciousness. Retrieved from http://www.psychology-online.net/articles/doc-30.html (in Rus).

10. Erahtin A. V. (1989). Dyalektyka stanovlenyia mushlenyia y soznanyia. Dialectics of the formation of thinking and consciousness. Sverdlovsk (in Rus).

11. Leontiev A. N. (1977). Deiatelnost. Soznanye. Lychnost. Activity. Consciousness. Personality. Moskow: Politizdat (in Rus).

12. Literatura "potoku svidomosti". Dukhovnyi svit personazhiv, ne poviazanyi z realnistiu. Literature of "the stream of consciousness". The spiritual world of characters, not related to reality. Retrieved from http://stud.com.ua/13034/kulturologiya (in Ukr).

13. Loy A. N. (1988). Soznanye kak predmet teoryy poznanyia. Consciousness as a subject of the theory of cognition. Kyiv, (in Rus).

14. Luria A. R. (1979). Yazyk i soznanye. Language and Consciousness. Moskow, 320 p. (in Rus).

15. Mamardashvili M. K. \& Pyatigorsky A. M. (1977). Symvol y soznanye. Symbol and Consciousness. Moskow (in Rus).

16. Metod "potoku svidomosti" u tvorchosti Dzh. Dzhoisa. The method of "the stream of consciousness" in the work of J. Joyce. Retrieved from http://pidruchniki.com/12631113/literatura (in Ukr).

17. Mikhailov F. T. (1990). Obshchestvennoe soznanye y samosoznanye yndyvyda. The public consciousness and self-consciousness of the individual. Moskow (in Rus). 
18. Neumann E. (1988). Proyskhozhdenye y razvytye soznanyia. The Origins and History of Consciousness. Moskow: Refl-book; Kyiv: Wakler (in Rus).

19. Osnovni idei fenomenu "potoku svidomosti" Viliama Dzheimsa. The main ideas of the phenomenon of "stream of consciousness" by William James. Retrieved from http://naub.oa.edu.ua/2014/osnovni-ideji (in Ukr).

20. Putnam H. (1990). Fylosofyia soznanyia. Philosophy of Consciousness. Moskow (in Rus).

21. Petukhov O. V. Svidomist yak predmet psykholohii. Consciousness as an object of psychology. Retrieved from http://psychologis.com.ua/soznanie_kak predmet psihologii.htm (in Ukr).

22. Polyakov O., (2011). Fenomenolohyia psykhycheskykh reprezentatsyi. Phenomenology of psychical representations. St. Petersburg: Piter (in Rus).

23. Spirkin A. G. (1972). Soznanye y samosoznanye. Consciousness and self-awareness. Moskow (in Rus).

24. Tvorchist D. Dzhoisa i shkola "potoku svidomosti”. D. Joyce's creativity and the school of "stream of consciousness". Retrieved from http://ukrbukva.net/ 3425-Tvorchestvo-Dzheiymsa-Dzhoiysa (in Ukr).

25. Tymosh Yu. V. Psykhosemantychni doslidzhennia svidomosti oosobystosti. Psychosemantic studies of consciousness of personality. Retrieved from http://www.inforum.in.ua/conferences/16/25/169 (in Ukr).

26. Hunt G. T. (2004). O pryrode soznayia: s kohnytyvnyi, fenomenolohycheskoi y transpersonalnoi tochek zrenyia. About the Nature of Consciousness: From Cognitive, Phenomenological, and Transpersonal Perspectives. Moskow: OOO "Izd-vo AST" (in Rus). 